\title{
Impact of Sand on Hydraulic Turbine Material: A Case Study of Roshi Khola, Nepal
}

\author{
Laxman Poudel, Bhola Thapa, Bim P. Shrestha and Nabin K. Shrestha
}

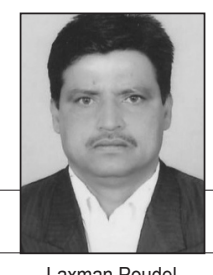

Laxman Poudel

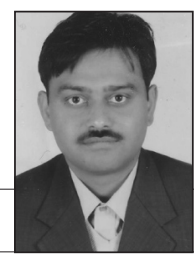

Bhola Thapa

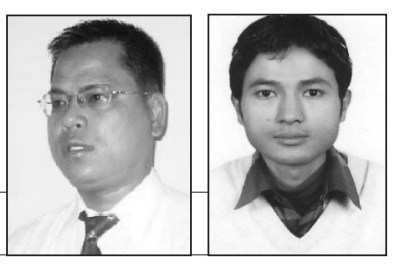

Bhim P. Shrestha

Abstract: Nepal is endowed by enormous water resources andpower potential, but not enough energy has been exploited from it. One reason is the deterioration of hydraulic turbines. Research on turbine erosion has shown that sand erodes the turbine material. Only a few researches however, have provided details of the many parameters of sand on the degradation of hydraulic turbines. This paper describes the different parameters of sand and the direct impact of sand on turbine material. The study of sand of the Roshi Khola (river) in Nepal shows that mineral content, size, shape and texture are the most important parameters of sand, with different characteristics and their impact on hydraulic turbines. Different methods like using a sieve analyzer to characterize size, microscopic observation after acid wash technique to characterize mineral content, and image processing to characterize and count particle shape are utilized to characterize sand. Sand samples from 20 stations on the Roshi Khola are used in this study. Most of the sampling locations are proposed hydropower project sites and confluences of tributaries. The erosion tests were carried out on turbine material in a High Velocity Erosion Test Rig at Kathmandu University. It was found that hardness, size, and shape are important parameters concerning their effects on erosion of hydraulic turbines. Even a short river like the Roshi Khola shows different sand characteristics at different locations and that they have different erosion rates.

Key words: Hydraulic turbine, sand particles, turbine erosion, mineral content, Nepal

\section{Introduction}

$\mathbf{H}$ ydraulic turbines are used to convert water energy to mechanical energy and then to electrical energy by means of generators. Turbines are prone to damage by impact of sand. Sand has different eroding characteristics and varies according to its mineral content, size, shape and the roughness of its texture. Many researchers have explored this subject, but have not yet been able to totally describe turbine material that best fit to resist degradation by sand. Because sand is a most eroding and responsible particle, a detailed understanding of the subject is important.

Nepal is rich in hydropower resources, more than six thousands small and large streams and rivers flow from the high mountains and hills to the flat lands of the Terai region. Among them, the Roshi Khola is a river with high potential that originates in the mid-hills and ends joining the Sun Koshi River. This study has been done to provide a more detailed understanding of sand of the Roshi Khola, so that hydropower investors can benefit by choosing efficient materials for turbine.

\section{Material and Methods \\ Sample collection}

Sand was sampled from 20 different strategic locations from the Roshi River's origin to its confluence with the Sun Koshi, considering human interference zone, tributary junctions, and industries. Samples from riverbed, bank and fluvial were collected by using different sampling equipment. Ten kilograms of samples were collected from each location and brought to the laboratory at Kathmandu University for various analyses.

\section{Sieve analyzer}

One of the most important parameters that have great impact on turbine material is sand particle size. To distinguish particle size, a six-layered sieve analyzer was used. Five $\mathrm{kg}$ of sand from each of 20 different locations were sieved to categorize the particles into six different sizes. In general, sand sizes between $90 \mu \mathrm{m}$ to $200 \mu \mathrm{m}$ are more prone to cause effects on turbine material. Other big particles are filtered before entry into turbine section. In this study sand is categorized in six categories as shown in Table 1.

\begin{tabular}{|c|c|c|c|c|c|c|}
\hline Sieve No. & 1 & 2 & 3 & 4 & 5 & 6 \\
\hline Size $(\mu \mathrm{m})$ & $>500$ & $425-500$ & $300-425$ & $212-300$ & $90-212$ & $<90$ \\
\hline
\end{tabular}

Table 1. Sieve Analyzer Size.

\section{Mineral content}

Sand particles contain different minerals and are inhomogeneous fragments of quartzite, meta sandstone, gneiss, phyllite, slate, carbonates, etc. Pebbles and coarse sands dominate over silt and fines. Pebbles are separated from the sediment samples. The pebbles are analyzed and their compositional representations are categorized separately. Similarly, a binocular microscope is used to examine sediments smaller than $2 \mathrm{~mm}$ (i.e., sand and fines). It is found that the sediment contains some amount of carbonates, minerals and rock fragments. So to determine the carbonate proportion in the sample an acid wash technique was carried out. For this purpose, samples were treated with 10\% dilute hydrochloric acid. Weight loss after reaction was measured as the carbonate content in the minerals.

\section{Shape}

An image processing technique was utilized to determine the morphology of sand particles. Different shapes of sand particles are inherent in nature, so to 
distinguish them, sand particles shape morphology was used to know different shapes by utilizing Fast Fourier Transform. Shape descriptors were utilized to analyze different complex shape nature of sediments. Complex Fourier function with shape descriptors was utilized to characterize particles more efficiently. The analysis was done in the complex Fourier boundary of the particle. Coordinate field describes particles according to number of different descriptors and has real and imaginary parts, and is governed by boundary descriptor points that are expressed mathematically as complex function;

$x_{m}+i y_{m}=\sum_{n=-N / 2+1}^{+N / 2}\left(a_{n}+i b_{n}\right)\left[\cos \left(\frac{2 \pi n m}{M}\right)+i \sin \left(\frac{2 \pi n m}{M}\right)\right]$

Where $\mathrm{x}, \mathrm{y}$ are coordinates describing the particle

$\mathrm{N}$ is the total number of descriptors

$\mathrm{n}$ is the descriptor number

$\mathrm{M}$ is the total number of points describing the particle

$\mathrm{m}$ is the index number of a point on the particle

$\mathrm{a}, \mathrm{b}$ are coefficients for each descriptor

i denotes an imaginary number

\section{Shape analysis}

A Matrox Imaging Library (MIL) application and MatLab 6.5 platform inbuilt program was used to determine the Fourier Descriptors for each sand particle. In order for the Fast Fourier Transform (FFT) to be correctly carried out for each sand particle, its perimeter is required to be broken into steps of equal length. Therefore, the length of each sand perimeter was assessed and broken into 128 equal lengths to produce 128 new coordinates. In order to reproduce sand in the space domain from the FFT, both the real and imaginary elements of the frequency domain must be maintained as separate; i.e. both the magnitude and the phase angle are required.

Figure 1 below shows a typical profile of a sand particle as reconstructed using Fourier descriptors in this manner. Figure 1(a) gives the original profile as output by the image analysis programmed whilst Figures 1(b) to $1(\mathrm{f})$ show the effect of reducing the information by suppressing greater numbers of the higher order descriptors and its descriptors are $+/-64,+/-24,+/-8$, $+/-5,+/-3$. The fine detail is increasingly lost but the overall morphology is retained. The data for this were output to a text file for each sand type. The coefficients were further analyzed using a spreadsheet to produce statistical data. The $\mathrm{x}, \mathrm{y}$ coordinates are taken as real and

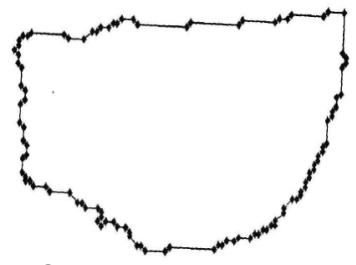

(a) Original Digitized

Outline of Particle

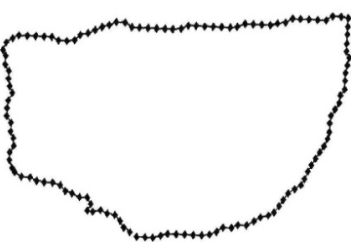

(b) +/- 64 Fourier Descriptors

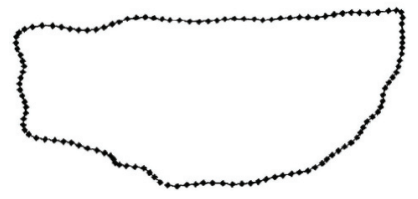

(c) $+/-24$ Fourier

Descriptors

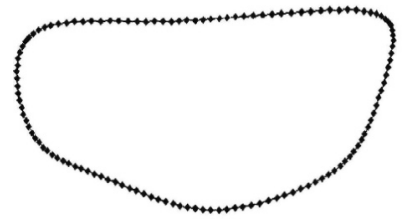

(e) $+/-5$ Fourier

Descriptors

Figure 1. The Effect of Reconstruction of a Particle from Complex Fourier Descriptors using Successively Fewer Descriptors.

imaginary for the complex Fourier analysis.

The impact of sand particles on turbine material $16 \mathrm{Cr} 4 \mathrm{Ni}$ has already been studied (Thapa 2004) and its result has also been interpreted on the basis of size and mineral content. But the effect of shape was not analyzed at that time because it is cumbersome to study impact of shape due to large abundance and nature of different shape particles in single location sample; thus, different techniques for analyzing shape are needed. Therefore, shape feature extraction was done after the impact study. This approach of defining shape and its impact study is fruitful and worthy. Only two gram of sand was taken as reference to characterize and quantify shape.

Matrox Imaging Library software was utilized to count sand particles present in 2 gram of sand samples from each of the 20 sites of the Roshi River. The software calculates the number of particles captured by Charge Coupled Device (CCD) camera, after which complex Fourier Descriptor Analysis was done to extract the shape of particles. This process includes image reading, segmentation, defining classifier and descriptor analysis using image processing. It gives the particle shape of each site sample quantitatively. Later on an analytical method of data correlation is used to make the impact analysis. This work presents the impact of the amount of sand particles and different shapes present in that sample quantitatively. Sand shapes are quantitatively analyzed by the above method with its descriptors and presented simply to show which, what and how many types of shapes were there while testing sand impact on turbine material.

\section{Sand erosion test rig}

The experimental setup, High Velocity Jet Erosion Test Rig at Kathmandu University (Figure 2) is used to determine the erosive rate. It consists of a nozzle to accelerate sand particles which strikes on test specimen at desired velocity. Sand is mixed in the conical Hooper shaped mixing tank. The tests are carried out for fixed 
flow rate, sand size, quantity and test time.

The test circuit has $5.5 \mathrm{~kW}$ mono block centrifugal pumps with $45 \mathrm{~m}$ head, with a six liters per second discharge rate. Valves were used to control the flow of water and sand particles. The sand was weighed and filled into $1.5 \mathrm{~m}$ height hopper 10omm ahead of the nozzle. Once the pump was started and the water circulated through the nozzle, the valve of the sand hopper was opened. The water creates turbulences inside the hopper and sand falls down in the horizontal pipe due to gravity. The increased velocity of the water helps the sand particles to flow continuously through the nozzle. The test was continued until all the sand particles passed through the nozzle. For one test $1.5 \mathrm{~kg}$ of sand was used and it took about 20 minute to pass all the sand particles from the nozzle.

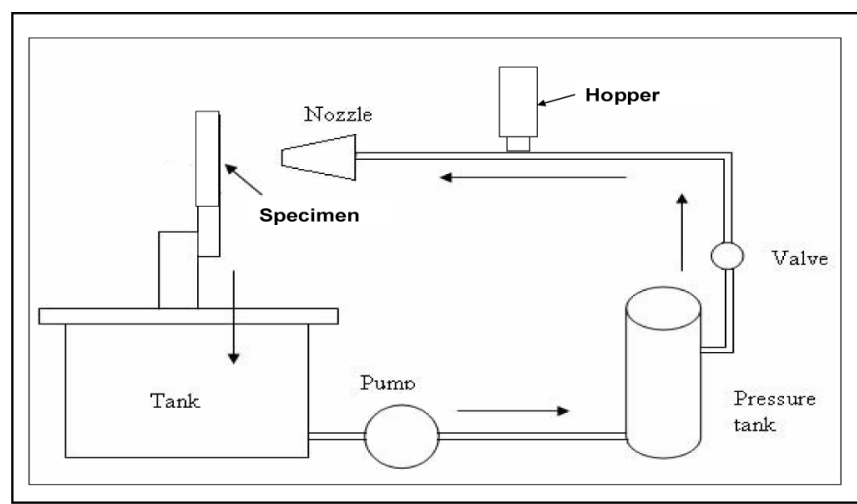

Figure 2. Test Rig for Sand Erosion.

\section{Test procedure}

All the activities in the erosion test in high velocity jet impingement test were manual, and all observations and data were recorded manually:

- Cleaning the specimens with acetone, drying the specimens in air and weighing;

- Clamping the specimens in the test rig, and starting the pump for 20 minutes;

- Removing the specimens from the test rig after all the sand particles passed through the nozzle;

- Cleaning and drying the specimens, weighing the specimens after erosion; and,

- Recording the weight loss of the specimens.

\section{Result and Discussion}

\section{Mineral content}

Mineral content report was taken and represented by four different samples, each representing five locations (spots). Quartz and feldspar were the dominant minerals in the sediment sample, and mica containing muscovite and biotitic occurred in minor amounts. On tables below from Table 2 to Table 5, 'others' identified as 'A' represent relatively hard minerals like tourmaline, hornblende and garnet and also rock fragments; similarly, others marked as 'B' represent softer minerals like carbonates, phogophite and sericite as clay minerals.

\begin{tabular}{|c|c|c|c|c|c|c|}
\hline \multirow{2}{*}{\multicolumn{2}{|c|}{ Minerals }} & \multicolumn{3}{|c|}{ Sample (\%) } & \multirow{2}{*}{$\begin{array}{c}\text { Average } \\
(\%)\end{array}$} & \multirow{2}{*}{$\begin{array}{l}\text { Hardness } \\
\text { (Moh's Scale) }\end{array}$} \\
\hline & & 1 & 2 & 3 & & \\
\hline \multicolumn{2}{|c|}{ Quartz } & 61 & 68 & 54 & 61 & 7 \\
\hline \multicolumn{2}{|c|}{ Feldspar } & 21 & 14 & 20 & 18 & 6 \\
\hline \multicolumn{2}{|c|}{ Mica } & 3 & 3 & 3 & 3 & 2 to 3 \\
\hline \multirow{2}{*}{ Others } & A & 7 & 8 & 14 & 10 & $\geq 5$ \\
\hline & B & 8 & 7 & 9 & 8 & $<5$ \\
\hline
\end{tabular}

Table 2. Grain Size: <2mm, Spot Nos. 16, 17, 18, 19 \& 20.

\begin{tabular}{|c|c|c|c|c|c|c|}
\hline \multirow{2}{*}{\multicolumn{2}{|c|}{ Minerals }} & \multicolumn{3}{|c|}{ Sample (\%) } & \multirow{2}{*}{$\begin{array}{c}\text { Average } \\
(\%)\end{array}$} & \multirow{2}{*}{$\begin{array}{l}\text { Hardness } \\
\text { (Moh's Scale) }\end{array}$} \\
\hline & & 1 & 2 & 3 & & \\
\hline \multicolumn{2}{|c|}{ Quartz } & 55 & 59 & 44 & 53 & 7 \\
\hline \multicolumn{2}{|c|}{ Feldspar } & 14 & 12 & 12 & 13 & 6 \\
\hline \multicolumn{2}{|c|}{ Mica } & 15 & 7 & 1 & 7 & 2 to 3 \\
\hline $\begin{array}{l}\text { Oth- } \\
\text { ers }\end{array}$ & A & 7 & 14 & 37 & 19 & $\geq 5$ \\
\hline
\end{tabular}

Table 3. Grain Size: < 2mm, Spots Nos. 11,12,13,14 \& 15.

\begin{tabular}{|c|c|c|c|c|c|c|}
\hline \multirow{2}{*}{\multicolumn{2}{|c|}{ Minerals }} & \multicolumn{3}{|c|}{ Sample (\%) } & \multirow{2}{*}{$\begin{array}{c}\text { Average } \\
(\%)\end{array}$} & \multirow{2}{*}{$\begin{array}{c}\text { Hardness } \\
\text { (Moh's Scale) }\end{array}$} \\
\hline & & 1 & 2 & 3 & & \\
\hline \multicolumn{2}{|c|}{ Quartz } & 45 & 54 & 50 & 50 & 7 \\
\hline \multicolumn{2}{|c|}{ Feldspar } & 23 & 19 & 21 & 21 & 6 \\
\hline \multicolumn{2}{|c|}{ Mica } & 19 & 7 & 5 & 10 & 2 to 3 \\
\hline \multirow{2}{*}{ Others } & A & 4 & 11 & 18 & 11 & $>5$ \\
\hline & B & 9 & 9 & 6 & 8 & $<5$ \\
\hline
\end{tabular}

Table 4. Grain Size: <2mm, Spot Nos. 6, 7, 8, 9 \& 10.

\begin{tabular}{|c|c|c|c|c|c|c|}
\hline \multirow{2}{*}{\multicolumn{2}{|c|}{ Minerals }} & \multicolumn{3}{|c|}{ Sample (\%) } & \multirow{2}{*}{$\begin{array}{c}\text { Average } \\
(\%)\end{array}$} & \multirow{2}{*}{$\begin{array}{c}\text { Hardness } \\
\text { (Moh's Scale) }\end{array}$} \\
\hline & & 1 & 2 & 3 & & \\
\hline \multicolumn{2}{|c|}{ Quartz } & 59 & 53 & 33 & 48 & 7 \\
\hline \multicolumn{2}{|c|}{ Feldspar } & 22 & 20 & 15 & 19 & 6 \\
\hline \multicolumn{2}{|c|}{ Mica } & 6 & 1 & 2 & 3 & 2 to 3 \\
\hline Others & A & 4 & 18 & 41 & 21 & $>5$ \\
\hline
\end{tabular}

Table 5. Grain Size: <2mm, Spot Nos. 1, 2, 3, 4 \& 5 .

Mineral content analysis has shown that 20 to $30 \%$ of sediments are of pebble size. The composition of pebbles were sub-rounded to sub-angular rock fragments of quartzite, metasandstone, gneiss, phyllite, slate, carbonates, etc. Similarly, the silt and sands are dominating with quartz minerals along with feldspar and some tourmalines, micas, calcite and a few others.

It was found that the sediment contains some amount of carbonate minerals and rock fragments. So, to determine the carbonate proportion in the sample, an acid wash technique was carried out. For this purpose, samples were treated with $10 \%$ dilute hydrochloric acid. 
The weight loss after reaction was taken as the carbonate content in the minerals. It was found that carbonate present in the sediments was about $5 \%$ on average. The sediment smaller than $60 \mu$ are difficult to observe under a binocular microscope, hence the composition below this size is ignored due to uncertainty in observation. It was observed that sand particles contained $48-61 \%$ of quartz, $13-21 \%$ of feldspar, $3-10 \%$ of micron and $10-21 \%$ of hard minerals like tourmaline, hornblende and 8-9\% of softer minerals like carbonates, phogophite as clay minerals.

\section{Erosion due to size}

Erosion test results were represented in terms of weight loss (in $\mathrm{mg}$ ) of specimen in $\mathrm{Y}-\mathrm{Y}$ axis and number of locations in the $\mathrm{X}-\mathrm{X}$ axis. Figure 3, below, shows that for sand size of 300-425 microns the erosion rate was higher compared to smaller size particles shown in Figure 4. This erosion rate according to size of particles is in line with the impact energy due to the particles in all sizes as shown in Figure 3-6. The trends of erosion in different locations are also similar for all sizes but magnitudes are different.

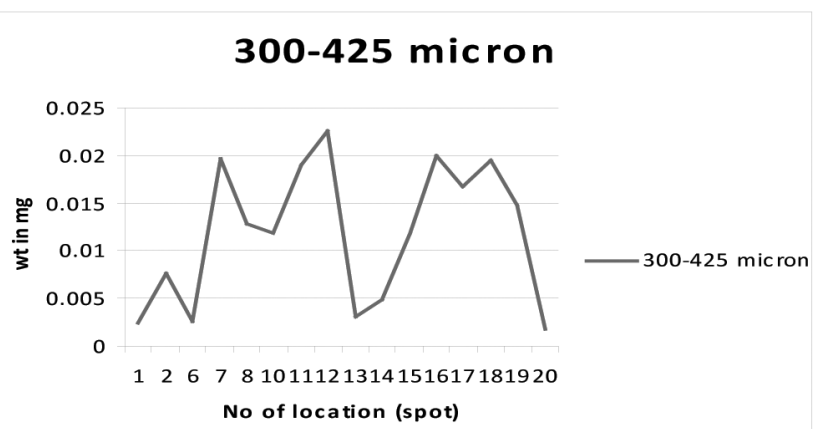

Figure 3. Weight Loss of Turbine Material due to 300-425 Micron Sand Particles.

\section{2-300 micron}

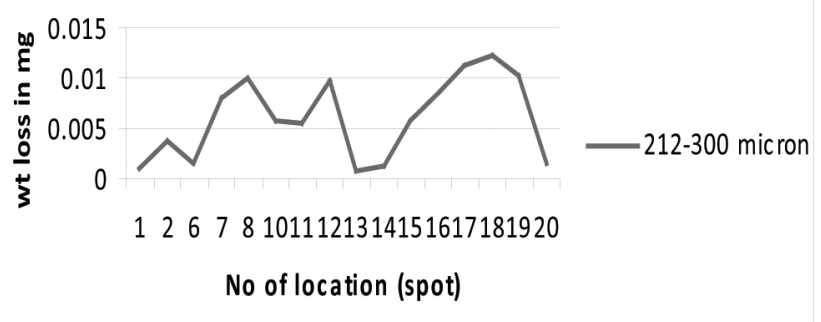

Figure 4. Weight Loss of Turbine Material due to 212-300 Micron Sand Particles.

Figure 5 shows that for sand size 90-212 microns the erosion rate is higher in locations 16,17 up to $0.012 \mathrm{mg}$., while for sand size $<90$ microns the erosion rate is higher in location 18 and 19 up to $0.0075 \mathrm{mg}$ and lower in 6, 12 and 13 in both the cases.

\section{0-212 micron}

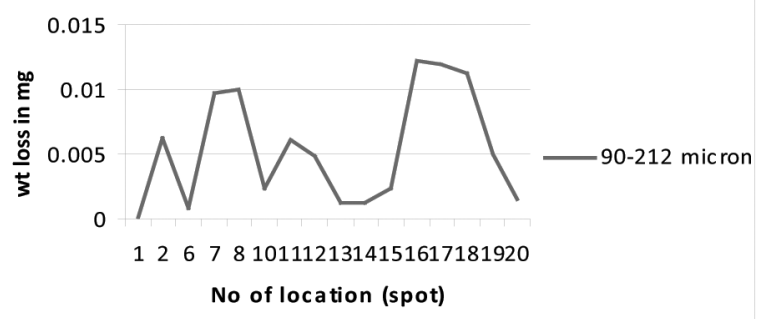

Figure 5. Weight Loss of Turbine Material due to 90-212 Micron Sand Particles.

\section{$<90$ micron}

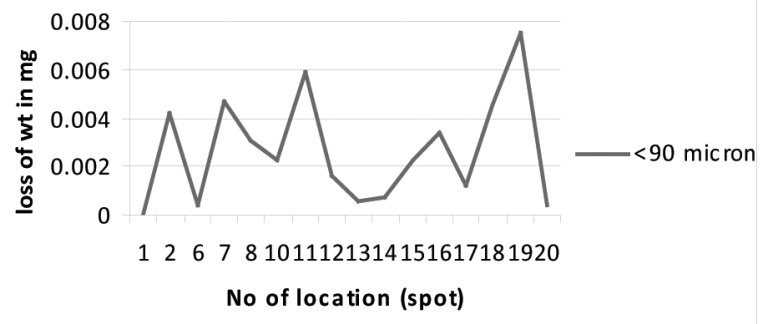

Figure 6. Weight Loss of Turbine Material due to Smaller than 90Micron Sand Particles.

In Figure 6, weight loss of the specimens is higher in locations 16, 10 and 12 for sand size of 300-425 microns. In contrary to other observations of less erosion in downstream of the river (Thapa 2004), the erosion at downstream of this river are higher. The reason for this could be accumulation of sand with hard minerals in the downstream.

\section{Erosion due to shape}

Shape were identified by image processing and its impact was found by the above test rig experiment. Particles ranged from 425 to 90 microns are abundant and responsible for degradation of turbine material. Particles of these sizes were categorized into four different ranges acccording to sieve size. Shape analysis was done using image processing by Matrox Imaging Library and MatLab. Twenty one different shapes were traced out by image processing and Fourier Transform. Matrox Imaging software helps to find out the total sand particles flowing with water that hits the turbine blade. These 21 different shapes of sand were used to find out the total impact of different shape of sand particles. According to these features complex Fourier descriptor has given extended different shapes. Total 21 numbers of complex shapes are defined as in Table 6 which shows type and its specific shape morphology. 


\begin{tabular}{|c|c|}
\hline $\begin{array}{c}\text { Sand Type } \\
\text { Index }\end{array}$ & Sand Shape Specific Name \\
\hline 1. & Well rounded with high sphericity \\
\hline 2. & Well rounded with low sphericity \\
\hline 3. & Rounded with high sphericity \\
\hline 4. & Rounded with low sphericity \\
\hline 5. & Sub rounded with high sphericity \\
\hline 6. & Sub rounded with low sphericity \\
\hline 7. & Rounded angular with high sphericity \\
\hline 8. & Rounded angular with low sphericity \\
\hline 9. & Low angular with high sphericity \\
\hline 10. & Low angular with low sphericity \\
\hline 11. & High angular with high sphericity \\
\hline 12. & High angular with low sphericity \\
\hline 13. & Slight Elongation (E) \\
\hline 14. & Moderate Elongation (E) \\
\hline 15. & High Elongation (E) \\
\hline 16. & Slight square (S) \\
\hline 17. & Moderate square (S) \\
\hline 18. & High square (S) \\
\hline 19. & Slight triangular (irregular) $(\mathrm{T})$ \\
\hline 20. & Moderate triangular (irregular) $(\mathrm{T})$ \\
\hline 21. & High triangular (irregular) $(\mathrm{T})$ \\
\hline
\end{tabular}

Table 6. Sand Shape Description.

Roshi River sand particles shape were characterized by 21 different shapes and are named according to its most common identified shape name. Sand particles shape impact on test material was studied parallelly with sand size and mineral content. Figure 7 below shows average variation in different sand particles shape of Roshi River. $\mathrm{X}$ axis shows 21 different shapes and $\mathrm{Y}$ axis shows sand particles shape average count.

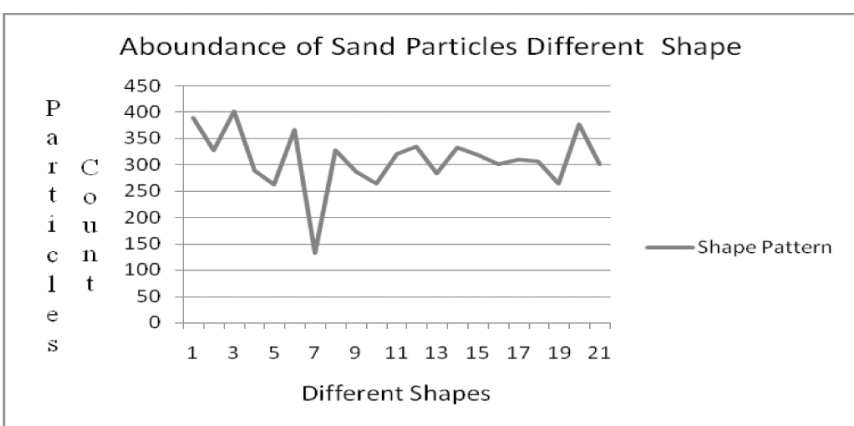

Figure 7. Sand Shape Types and its Quantity in Roshi Khola.

Sand particles shape have following pattern (Figure 7) of aboundance on different segment of Roshi River. Shape of type 1 i. e. well rounded with high sphericity and 3 rounded with high sphericity has high sediment particles in Roshi River whereas type 7 i.e rounded angular with high sphericity has less sediment particles. Other sand particles shapes are in same quantity range showing with shape type 20 with little more aboundance.

\section{Conclusion}

The study of turbine deterioration by the impact of fine sediments is important. Many power plants shut down due to early deterioration of turbine material, so it is necessary to consider all the parameters that deteriorate. This research focuses on sand as one of the most eroding elements, so its characteristics and impact values were studied. Data on different parameters of sand, i.e., size, shape and mineral content and their impact on turbine material, were studied. According to size of sand large sand particle have high effect than the smaller one. Sand of 300-425 micron size have highest impact value than other smaller sand particles following least impact value with smaller than 90 micron sediment particles. Spot no 16 and 17 of Roshi River sediment have high eroding characteristic. Quartz and Feldspar are the dominant mineral content found in sediment of Roshi River and have high hardness value than other minerals. Location (site nos.) 11, 12, 13, 14 and 15 have less erosive effect on turbine materials on the basis of mineral content. It is also observed that sand particles of type 9, 10, 11, 19 are most dominant kind of shape that have high impact value, these types of sand are sharp and irregular in shape while as type 1, 2 and 7 have less impact value with round in shape, whereas the quantity of sediments at upstream of the river are more sharp and irregular and following downstream are rounded type.

It is depicted that greater the size greater is the impact and from shape point of view triangular and irregular type of sand is found little and have high erosive effect on turbine material while as square with high elongation are in low amount. Angular shape particles yield in high amount then the irregular one. So it can be concluded that sand particles shapes changes as river transports the sediments from upstream to downstream. The result shows that most of the particle converts to type 10 , i.e. angular with low sphericity and type 6 , i.e. sub rounded with low sphericity which is found abundant at downstream in case of Roshi Khola.

Laxman Poudel is a PhD candidate, Kathmandu University, School of Engineering, Mechanical Department. Hisresearchisonsanderosionon hydraulic turbine materials and sediment characterization. He has been an employee of Tribhuwan University, Institute of Engineering as a Lecturer in the Mechanical Department.

Corresponding address: p12_laxman@yahoo.com.

Prof. Dr. Bhola Thapa, is Dean of School of Engineering, Kathmandu University. His $P h D$ dissertation was on sand erosion on hydraulic machineries, at the Norwegian University of Science and Technology (NTNU) in 2004. 
Corresponding address: bhola@ku.edu.np.

Associate Prof. Dr. Bim Prasad Shrestha, is Head of Department, School of Engineering, Mechanical Department, Kathmandu University.

Corresponding address: shrestha@ku.edu.np.

Nabin Kumar Shrestha is a Research Fellow, B.E. Mechanical, from Kathmandu University. $\quad H e$ is now with Review Resource Nepal Consulting Firm of Kathmandu.

Corresponding address: kumar_nab@yahoo.com.

\section{References}

Thapa, B., 2004, Sand Erosion in Hydraulic Machinery, doctoral dissertation, Norwegian University of Science and Technology, Faculty of Engineering Science and Technology. URL: urn.kb.se/ resolve?urn=urn:nbn:no:ntnu:diva-302.

\section{Other Relevant Bibliography}

Bajracharya, T.R., D. Sapkota, R. Thapa, S. Poudel, C.B. Joshi, R.P. Saini and O.G. Dahlhaug, 2006a, 'Comparative study of Pelton turbines with sand led erosion test and numerical flow analysis', Journal of The Institute Of Engineering, Tribhuwan University, Nepal.

Bajracharya, T.R., D. Sapkota, R. Thapa, S. Poudel,
C.B. Joshi, R.P. Saini and O.G. Dahlhaug, 2006b, 'Correlation study on sand led erosion of buckets and efficiencylossesinhighheadpowerplants',Proceedings of First National Conference on Renewable Energy Technology for Rural Development, 12-14th October Kathmandu, Nepal.

Blott, S.J. and K. Pye, 2008, 'Particle shape: A review and new methods of characterization and classification', Sedimentology, v. 55, pp.31-63.

Bowman, E.T., K. Soga and T.W. Drummond, 2000, 'Particle shape characterization using Fourier Analysis', CUED/D-Soils/TR, v. 315.

Byerly, G.R. and J.V. Mrakovich, 1997, Use of Fourier Shape Analysis in Zircon Petrogenetic Studies, The Geological Society of America Bulletin, v.86(7), pp.956-958. URL: gsabulletin.gsapubs.org/ content/86/7/956.

Laghari, M.S., Q.A. Memon and G.A. Khuwaja, 2005, 'Knowledge based wear particle analysis', Ingernational Journal of Information and communication Engineering v.1(7), pp.316-320. URL: www.waset.org/journals/ijice/v1/v1-7-61.pdf.

Mancino, C., P. Landschoot and A. McNitt, 1997, Methods of Classifying Sand Shape and the Effects of Sand Shape on USGA Specifications Rootzone Physical Properties, Executive Summary, 1997 Annual Report. URL: turf.lib.msu.edu/ressum/1996/82.pdf.

\section{CALENDAR OF EVENTS - ENVIRONMENT}

17-18 February, 2012: Carbon Management. Location: Edinburgh Napier University, UK. More info: www.euenergycentre.org/training/trainingcourses/142-carbon-management.

24-26 February, 2012: International Conference on Environmentally Sustainable Urban Ecosystems (ENSURE 12). Location: Guwahati, Assam, India. More info: www.iitg.ernet.in/coeiitg/ensure.html.

26-28 February, 2012: International Conference on Climate Change and Humanity (ICCCH 2012). Location: Singapore. More info: www.iccch.org/.

26-28 February, 2012: 2nd Internal Conference on Future Environment and Energy (ICFEE 2012). Location: Singapore. More info: www.icfee.org/.

7-9 March, 2012: EcoForum Conference and Exhibition. Location: Sidney, NSW, Australia. More info: www.ecoforum.net.au/2012/.

12-18 March, 2012: Climate Week. Location: London, UK. Contact Email: enquiries@climateweek.com. More info: www.climateweek.com/.

26-29 March, 2012: Planet under Pressure. Location: London, UK. More info: ccafs.cgiar.org/events.

28-30 March, 2012: South-East European Solar Exhibition. Location: Sofia, Bulgaria. More info: www.eeandres.viaexpo.com/en/exhibition/.

7-8 April, 2012: 2nd International Conference on Environment Science and Engineering (ICESE 2012). Location: Bangkok, Thailand. More info: www.icese.org/index.htm.

14-17 May, 2012: 7th Annual International Symposium on Environment. Location:

Athens, Greece. More info: www.atiner.gr/ environment.htm.

22-24May,2012: Sustainabilitylives!'TheUK'sleading water, energy, environmental, land, and sustainable business exhibition. Location: Birmingham, UK. More info: www.sustainabilitylive.com/.

29-31 May, 2012: Mountain Resource Management in a Changing Environment. Location: Kathmandu, Nepal. More info: www.himunet.com/downloads/ international-symposium-may-2012.pdf.

29-31 May, 2012: International Conference on Climate Adaptation 2012. Location: Tucson, USA. More info: www.ccafs.cgiar.org/events.

8-12 July, 2012: Global Conference on Global Warming. Location: Istanbul, Turkey. More info: www.gcgw.org. 